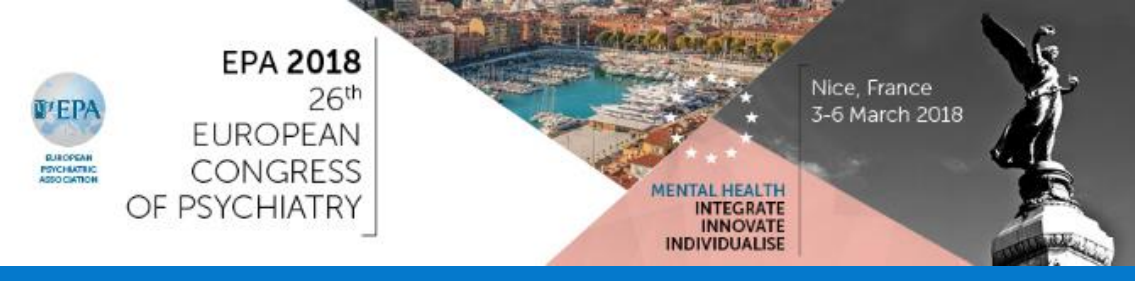

\title{
Is there a relationship between adherence to therapy and depressive symptoms in people facing type 1 and type 2 diabetes?
}

\author{
Ilda Massano-Cardoso ${ }^{1,2,4}$, Ana Galhardo1,3, Fernanda Daniel ${ }^{1,2}, \&$ Vitor Rodrigues $^{4}$
}

${ }^{1}$ Instituto Superior Miguel Torga

2 Centre for Health Studies and Research of the University of Coimbra (CEISUC)

${ }^{3}$ CINEICC - Faculty of de Psychology and Educational Sciences of the University of Coimbra

${ }^{4}$ Faculty of Medicine of the University of Coimbra

\section{Introduction}

Diabetes mellitus (DM) integrates a heterogeneous group of metabolic disorders characterized by the body's inability to maintain glucose homeostasis. Actually, this public health problem affected 425 million people in world, or $8.8 \%$ of adults from $20-79$ years. The number increases to 451 million if the age is expanded to 18-99 years. If these trends continue, by 2045, 693 million people will have diabetes. The centrality of the patient's role in selfadministered health care management is a crucial topic today as we focus on issues of adherence to the treatment of diabetes. In short, adherence to treatment does not imply simply the scrupulous following of the medical regimen; it also entails engaging in several health-related behaviours, such as eating behaviour or physical activity.

\section{Methods: A descriptive correlational study with cross-sectional design was} conducted. Patients attending diabetes consultations participated in the study $(\mathrm{N}=$ 347). Participants completed the Beck Depression Inventory (BDI) and adherence was established based on $\mathrm{HbA1c}$ criteria.

Results: The mean score on the BDI, for either DM type $1(M=7.74 ; S D=6.62)$ and type $2(M=9.38 ; S D=8.62)$, is higher than in general population (GP) $(M=$ 3.87; $S D=4.15)$. Mean comparisons between DM type 1 and GP as well as between DM type 2 and GP are statistically significant $(t=6.183 ; p<.001 ; t=8.47$; $\mathrm{p}<.001)$. The association between depression and adherence was significant in both types of DM $\left(X^{2}=5.86 ; p=.015 ; X^{2}=6.57 ; p=.010\right)$. DM type 1 and type 2 participants exhibit significant differences in the symptoms related to inability to work (“O”), sleep disturbances (“P”), fatigue (“Q”), weight loss ("S"), and loss of libido ("U"). Post-hoc tests revealed that median scores of these symptoms are lower for DM type 1 as compared to DM type 2.

Conclusions: The current study sought out to contribute to increase understanding of the relationship between diabetes mellitus and depression. In this context, it is important to highlight the distinction between depressive symptoms and the physical consequences inherent to Type 2 diabetes treatment given that they may easily be confounded. Hence, it is essential to consider that "depressive symptoms" may show different characteristics when examined for Type 1 Diabetes or Type 2 Diabetes patients. Furthermore patient-doctor relationship in the therapeutic setting plays a crucial role, not only due to different clinical characteristics of Type 1 and Type 2 Diabetes but also because both the health care professional and the patient must be aware of its implications and treatment specificities in order to reinforce adherence. There is also the possibility that negative mood plays a mediating role mobilizing survival strategies that activate adherence. In this regard the development of an assessment instrument able to capture the emotional impact of diabetes specific features would be relevant in the future.

\section{References}

Rottenberg, J. (2014). The depths: The evolutionary origins of the depression epidemic. New York: Basic Books.

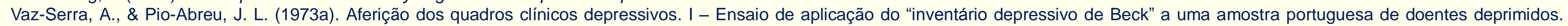
Coimbra Médica, XX, 623-644

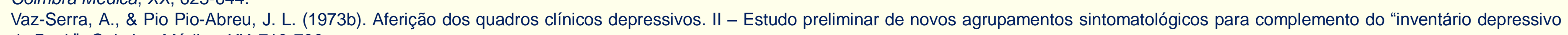
de Beck". Coimbra Médica, XX, 713-736.

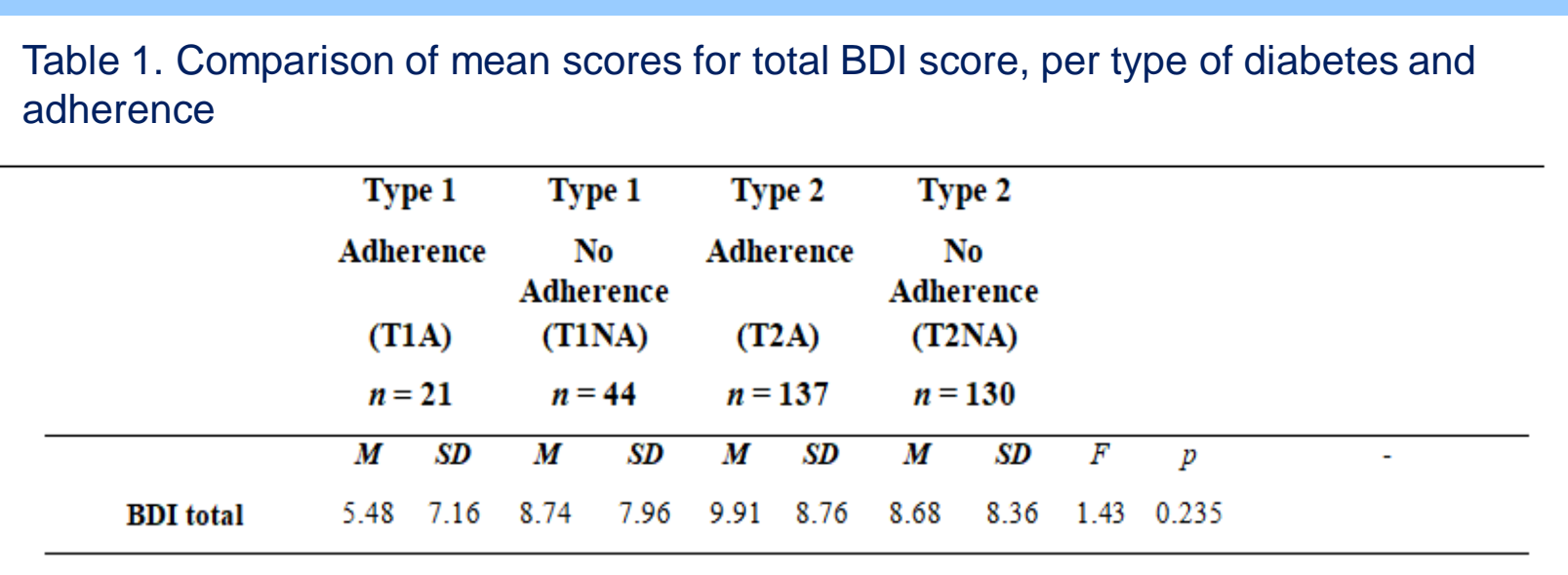

\section{Table 2. Items scores comparison}

\begin{tabular}{|c|c|c|c|c|c|c|}
\hline $\begin{array}{c}\text { Adherence } \\
\text { (T1A) } \\
n=21\end{array}$ & $\begin{array}{l}\text { Type } 1 \\
\begin{array}{c}\text { Non Adherence } \\
\text { (TlNA) } \\
n=44\end{array}\end{array}$ & $\begin{array}{c}\text { Adherence } \\
\text { (T2A) } \\
n=137\end{array}$ & $\begin{array}{l}\text { Non } 2 \\
\begin{array}{l}\text { Non Adherence } \\
\text { (T2NA) } \\
n=130\end{array}\end{array}$ & & & \\
\hline Symptoms & & & & $\mathrm{H}$ & $p$ & Post-hoc \\
\hline A & & & & 3.44 & 0.328 & \\
\hline B & & & & 3.95 & 0.266 & \\
\hline c & & & & 2.42 & 0.490 & \\
\hline D & & & & 4.8 & 0.187 & \\
\hline E & & & & 1.38 & 0.709 & \\
\hline $\mathrm{F}$ & & & & 6.93 & 0.074 & \\
\hline G & & & & 1.57 & 0.665 & \\
\hline $\mathrm{H}$ & & & & 6.19 & 0.103 & \\
\hline I & & & & 1 & 0.802 & \\
\hline J & & & & 1.22 & 0.749 & \\
\hline $\mathrm{K}$ & & & & 1.65 & 0.648 & \\
\hline L & & & & 3.77 & 0.287 & \\
\hline $\mathrm{M}$ & & & & 2.16 & 0.541 & \\
\hline $\mathrm{N}$ & & & & 3.75 & 0.289 & \\
\hline & & & & & & 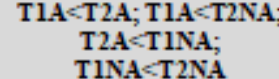 \\
\hline$Q$ & & & & 22.7 & $<0.001$ & TINA $<$ T2NA \\
\hline $\mathrm{p}$ & & & & 8.26 & 0.041 & $\mathrm{~T} 1 \mathrm{~A}<\mathrm{T} 2 \mathrm{~A}$ \\
\hline Q & & & & 9.64 & 0.02 & \\
\hline $\mathrm{R}$ & & & & 2.44 & 0.487 & \\
\hline s & & & & 17.3 & $<0.001$ & $\begin{array}{c}\mathrm{T} 1 \mathrm{~A}<\mathrm{T} 2 \mathrm{~A} ; \mathrm{T} 2 \mathrm{~A}<\mathrm{T} 1 \mathrm{NA} \\
\mathrm{T} 2 \mathrm{~A}\end{array}$ \\
\hline T & & & & 3.49 & 0.323 & \\
\hline $\mathrm{v}$ & & & & 25.6 & $<0.001$ & 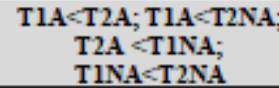 \\
\hline
\end{tabular}

